\title{
Elephants, gold standards and applied qualitative research
}

\author{
Nigel Fielding, University of Surrey.
}

\begin{abstract}
In a recent article in Qualitative Research, Norman Denzin discussed a variety of threats to qualitative research posed by institutional and professional organizational actors who would elevate Randomized Control Trials and associated practices as the gold standard indexing the quality of all social research. Informed by his long established contributions to the constantly changing field of research methodology, Denzin brought passion, and a rich variety of arguments, to the debate. I argue that this also brought some lapses of rigour that require attention if qualitative methodologists are to put their best case against the narrow and intolerant vision offered by the proponents of gold standards.
\end{abstract}

In his recent article in Qualitative Research (Denzin, 2009), Norman Denzin writes of 'the elephant in the living room'. Denzin's elephant is the threat posed by contemporary institutional moves to either valorize an antediluvian vision of qualitative research or dismiss this field of intellectual endeavour altogether by elevating Randomized Control Trials as the gold standard of all social research. These are real threats to graduate students, academics seeking tenure and researchers seeking funding. But this note discusses a different pachyderm, namely, Denzin's inconsistency of argument and lapses of rigour. My purpose is not to offer new arguments but to suggest ways to do justice to Denzin's arguments against the threat.

Point 1: effective resistance requires consistency of argument. Denzin contradicts positions of which he is himself the originator. For example, he criticizes mixedmethods research for failing to address incommensurability. Yet he authored what remains the defining exposition of mixed methods and sociological triangulation (Denzin, 1970). It would be valuable to know how Denzin connects his previous and current thinking. Currently, Denzin wants to condemn mixed methods as covert positivism or quasi-foundationalism.

This would be more compelling if Denzin used his authoritative grasp of mixedmethod practice to think himself into the head of the gold standards lobby advocating RCTs and give us a contemporary statement of the incommensurability argument that could be used against them. 'Incommensurability' is an absolutist argument, and absolutism surely presents problems for a field as alert to shades of grey as is qualitative research. Might incommensurability be a 'more or less thing'? Might some mixes of method be less wrong than others? Denzin believes that truth is always 'partial'. Agreed - so how can the 'truth' of incommensurability be absolute?

Similarly, Denzin ridicules a US disability research organization's call for criteria of 'credibility, transferability, dependability and confirmability', but Denzin himself offered those criteria, and this time it wasn't back in the 1970s. According to Denzin and Lincoln (1994: 14), criteria of 'credibility, transferability, dependability and 
confirmability replace the ... positivist criteria of internal and external validity, reliability and objectivity'. Now he suggests such a position is a mark of the 'science' approach he repudiates. Why were those criteria satisfactory in the 1990 s but not now?

Point 2: to carry arguments, accuracy is important. Denzin gets factual matters embarrassingly wrong. Any Brit who reads the statement about 'the British RAE' ( $p$. 143) would know that it is not a 'discourse advocating RCT'. British universities are, with one exception, state-funded, and the Higher Education Funding Council assesses the research that government pays for. As a generic system for evaluating research the RAE is indifferent to methodological debates. HEFC delegates the evaluations to panels of academics from the discipline whose output they are evaluating. Qualitative researchers are represented not only on sociology panels but in education, socio-legal studies, social policy, criminology, law, health studies ('subjects allied to medicine'), sport science, dance and theatre studies, and even psychology. Plenty of qualitative work was rated highly, including work in Denzin's preferred nonfoundationalist/feminist and communitarian vein.

Point 3: arguments are needed that generalize where warranted and reflect differences where appropriate. Denzin is best on his own ground - the situation in the USA, and particularly, in US educational research. The USA certainly does have a problem with recurrent hostility to qualitative research. But the USA is big, and Denzin overgeneralizes. His vision cannot accommodate, for instance, the 2008 conference on 'optimal coding of open-ended survey data' convened by the Institute of Social Research at the University of Michigan. The meeting explored how qualitative methods could extract more value from open-ended items on the American National Election Survey. Survey research does not come much more institutional than ANES. It is direct-funded by the US Congress and the current grantholders are an economist and a psychologist. Perhaps the gold standards straitjacket is not as tight as Denzin suggests.

The picture is more mixed in Europe, too. For instance, the Council of European Social Science Data Archives is currently promoting the archiving of qualitative data across Europe. State money is going into creating archives of exactly the kind of data the gold standards people think is worthless. Some national research com- munities in the US sphere of influence do ape 1950s US positivism but qualitative research endures even there (Saludadez and Garcia, 2001). Denzin offers a binary us/them vision in the same article as he argues that qualitative research's essential position is that there are many truths, all partial.

European institutional actors' efforts to set standards for qualitative research have been less crass than those of the US National Science Foundation. Qualitative research commissioned by UK government and other institutional bodies has been growing for some years. Denzin notes that the Cabinet Office commissioned the Spencer Review (Spencer et al., 2003) to set criteria. It is true that the criteria they produced were unwieldy but this reflects their inclusiveness. They do not rule out any form of qualitative research, are not formatted as a checklist but as a set of desiderata, and they emphasize discretionary interpretation. More important than Spencer, however, is the government's Competency Framework for Social Research. It (a) specifies that anyone employed by government as a social researcher must understand and demonstrate competence in qualitative methods; and (b) is couched in neutral terms with no suggestion that any particular method (e.g. RCTs) or analytic technique is necessarily superior to any other. The UK government continues regularly to commission qualitative research. There are similar circumstances in certain other European countries but on the strength of the British case alone it is arguable that 
Point 4: effective critique should accurately reflect opponents' positions. Denzin mischaracterizes positions he opposes. For instance, he lists 13 recommendations aimed at research agencies, publishers, and universities by the National Research Council. The recommendations are innocuous and do not bear on the gold standards dispute. Immediately after the list, Denzin summarizes Maxwell's critique of the NRC 'formulations'. Maxwell's critique cannot be about the recommendations, though, because Denzin's summary of Maxwell's critique doesn't include a single point that relates to the items on the list, which includes things like universities should 'ensure students develop deep methodological knowledge'. This sentiment may be banal but it also has no relevance to the attack on interpretivism that is Maxwell's (and Denzin's) concern. Similarly, Denzin goes on to assert that 'the NRC is clear on this point' (concerning the wonders of RCT) but instead of quoting NRC he quotes a commentary by Feuer et al. (2002). The unprepared reader cannot know whether Feuer et al. are characterizing the NRC position or asserting their own. We need to know what the NRC says.

Another example of mischaracterization is Denzin's repetition of an error from the first edition of his famous Handbook. He states that 'Nudist' (a qualitative software package) is a 'form of analysis'. No qualitative software package is a 'form of analysis', it is a tool that supports the 'form of analysis' the user wants to apply. It does not have an analytic approach built into it. That would be commercial suicide, apart from anything else. Like SPSS does for stats, qualitative software packages try to support the widest possible range of analytic approaches. This is primarily because most qualitative software developers are academics, but it also happens to maximize sales. The misconception that qualitative software is a distinct 'form of analysis' has been widely rebutted for some while (Lee and Fielding, 1991; Tesch, 1990). Moreover, does a singleword reference to an obsolete and oddly-named software package, without any further explanation, serve readers who may be unfamiliar with qualitative software?

Point 5: telling arguments employ logic and evidence without recourse to personalized authority. Denzin appears at times to be in dialogue with himself and not with the reader. For instance, his paragraph about data sharing appears to be the germ of a commentary on the archiving and secondary analysis controversy. But Denzin goes no further than a self-referential series of questions suggesting a hubristic, even selfish posture (paraphrasing, 'these data are mine and I am not going to share') without giving readers enough to understand why such a position might be warranted. A potentially damaging weakness in the gold standards position is treated as a throwaway line, as if it's enough for readers to know that the Collaborators want us to share and since they are nasty we should refuse.

Also tantalizingly incomplete is Denzin's commentary on blind peer review. The practice is lambasted but he does not discuss alternatives. This despite the fact that the scientific establishment he castigates includes a notably brave practice of signed reviews, a distinctive feature of one branch of US science funding. Some regard it as a more effective check on rigour than blind reviews (signed reviews make reviewers more accountable). There is a worthwhile debate to be had about different peer review formats but they are not configured along the gold standard/interpretivist binary. Some funders of qualitative research disclose reviewer and applicant identities and others don't. Some social research journals use double-blind reviews, some don't. If 'blind peer review' is the epitome of gold standard science then the qualitative field is as 
A final concern is the article's implication (particularly strong on p. 152) that the adoption of intellectual positions like postpositivism is done entirely in response to the American gold standards debate. Denzin implies that people take up intellectual stands and orientations in an effort to curry favour with, or show their resistance to, the US science establishment. That is both parochial and cynical. There are many reasons that people adopt an intellectual orientation. In the qualitative field, the kind of instrumentalism Denzin implies is probably rare, else why would we commit to methodologies whose warrant is endlessly contested?

Denzin's analysis almost wholly considers the current situation in the USA, with occasional and sometimes inaccurate mention of other places. In the context of his reference to Habermas and Bourdieu on 'global audit culture' this stands in danger of implying that the world's qualitative researchers adopt their intellectual affinities in reaction to the US situation. If a qualitative researcher from any other country were to claim that its situation determined the world's research interests that view wouldn't stand for a moment.

Having spent 31 years as a qualitative sociologist in an engineering university I share the opposition to the dirigisme and anti-intellectualism of the gold standards lobby by authorities like Denzin (2009) and Becker (2009). Righteous indignation is often a spur to creativity but in this debate we need arguments that will persuade rather than ones handing opponents an easy win.

\section{References}

Becker, H.S. (2009) 'How to Find Out How to Do Qualitative Research', URL: http://home.earthlink.net/ hsbecker/articles/NSF.html

Denzin, N.K. (1970) The Research Act: A Theoretical Introduction to Sociological Methods. Chicago, IL: Aldine.

Denzin, N.K. (2009) 'The Elephant in the Living Room: Or Extending the Conversation about the Politics of Evidence', Qualitative Research 9(2): 139-60.

Denzin, N.K. and Lincoln, Y.S. (1994) 'Introduction: Entering the Field of Qualitative Research', in N.K. Denzin and Y.S. Lincoln (eds) Handbook of Qualitative Research, pp. 1-18. London: Sage.

Feuer, M., Towne, L. and Shavelson, R. (2002) 'Science, Culture and Educational Research', Educational Researcher 31(8): 4-14.

Lee, R.M. and Fielding, N. (1991) 'Computing for Qualitative Research', in N. Fielding and R.M. Lee (eds) Using Computers in Qualitative Research. London: Sage.

Saludadez, J. and Garcia, P. (2001) 'Seeing our Quantitative Counterparts', Forum Qualitative Sozialforschung 2(1), URL: http://www.qualitative-research.net/index.php/ fqs/article/view/973/2123

Spencer, L., Ritchie, J., Lewis, J. and Dillon, L. (2003) Quality in Qualitative Evaluation. London: National Centre for Social Research.

Tesch, R. (1990) Qualitative Research: Analysis Types and Software Tools. New York: Falmer Press. 